\title{
Extensive odontogenic keratocysts of the maxilla: Review of the literature and report of six cases
}

\author{
Iain A Nish BSc MSc DDS, George KB Sándor MD DDS FRCDC FRCSC FACS, Simon Weinberg DDS FRCDC \\ Deparment of Oral and Maxillofacial Surgery, Faculty of Dentistry, University of Toronto; \\ The Hospital for Sick Children; Bloorview MacMillan Centre; The Toronto Hospital; The Doctor's \\ Hospital; Etobicoke General; and Humber Memorial Hospital, Toronto, Ontario
}

\begin{abstract}
IA Nish, GKB Sándor, S Weinberg. Extensive odontogenic keracysts of the maxilla: Review of the literature and report of six cases. Can J Plast Surg 1997;5(3):161-165. The clinical, radiological and histological features of six large maxillary odontogenic keratocysts are reviewed. Special treatment considerations for extensive maxillary lesions are discussed. Patient follow-up, including imaging studies, is important to allow the early detection and treatment of recurrent lesions when they are small and well localized.
\end{abstract}

Key Words: Basel cell nevus syndrome, Carnoy's solution, Maxilla, Odontogenic keratocysts

\section{Kystes kératiques odontogènes étendus au maxillaire : survol de la littérature et rapport de six cas}

RÉSUMÉ : Les caractéristiques cliniques, radiologiques et histologiques de six grands kystes kératiques odontogènes du maxillaire sont passés en revue. On présente ici les aspects thérapeutiques spéciaux appliqués aux lésions étendues du maxillaire. Le suivi du patient, y compris les examens d'imagerie, sont importants pour le dépistage précoce et le traitement des lésions récurrentes lorsqu'elles sont petites et localisées.

$\mathrm{O}$ dontogenic keratocysts (OKCs) arising in the maxilla are classically small, unilocular lesions that rarely involve the maxillary sinus. This paper familiarizes the plastic surgeon with the clinical, radiological and histological features of six extensive maxillary OKCs and the complications associated with their management.

\section{REVIEW OF THE LITERATURE}

The OKC is a clinically aggressive keratinizing epitheliallined cyst of the jaw. Phillipsen (1) first used the term 'odontogenic keratocyst', and it was described as a distinct entity by Shear in 1960 (2). Shear (2) and Pindborg and Hensen (3) subsequently documented its typical histological features. The majority of cysts grow slowly and asymptomatically at the expense of the medullary bone, and can become extensive before any clinical manifestations are apparent (4). Brannon (5) reported that $50 \%$ of all OKCs are detected as incidental findings on radiographs and the remainder are due to secondary infection. The $\mathrm{OKC}$ is notorious for its high recurrence

Correspondence and reprints: Dr George KB Sándor, The Hospital for Sick Children, Department of Dentistry, 555 University Avenue, Toronto, Ontario M5G 1X8. Telephone 416-813-6008, fax 416-813-6375,

e-mail gsandor@sickkids.on.ca rate, with reports ranging from $10 \%$ to $62 \%(2,3)$. In approximately $10 \%$ of cases $\mathrm{OKC}$ is associated with the basal cell nevus syndrome $(4,6)$; rarely it is linked to the development of malignancy.

OKCs account for between $3 \%$ and $11 \%$ of all jaw cysts $(6,7)$. OKCs occur predominantly in Caucasians $(5,6)$ and are more common in males than in females $(5,6,8)$. There is a wide age range of patients, with a peak frequency in the second and third decades $(5,6,9)$. OKCs found in the maxilla reportedly occur in older patients $(10,11)$. The mandible is affected more frequently than the maxilla (ratio $2: 1$ to $3: 1$ ) $(5,6)$. The majority of mandibular OKCs occur in the ramus and third molar area, followed by the first and second molar area and, lastly, the anterior mandible. In the maxilla, the third molar site is most common, followed by the canine region (2).

Radiographic features typically include a well demarcated, unilocular radiolucency in bone with a distinct sclerotic margin (10). However lesions can have scalloped margins, giving a multilocular appearance that is more frequent in larger lesions $(13,14)$. OKCs of the mandible exhibit little buccolingual expansion and may extend throughout the length of the bone. Although most have a distinct boundary of cortical bone, perforation of the cortical plates and in- 


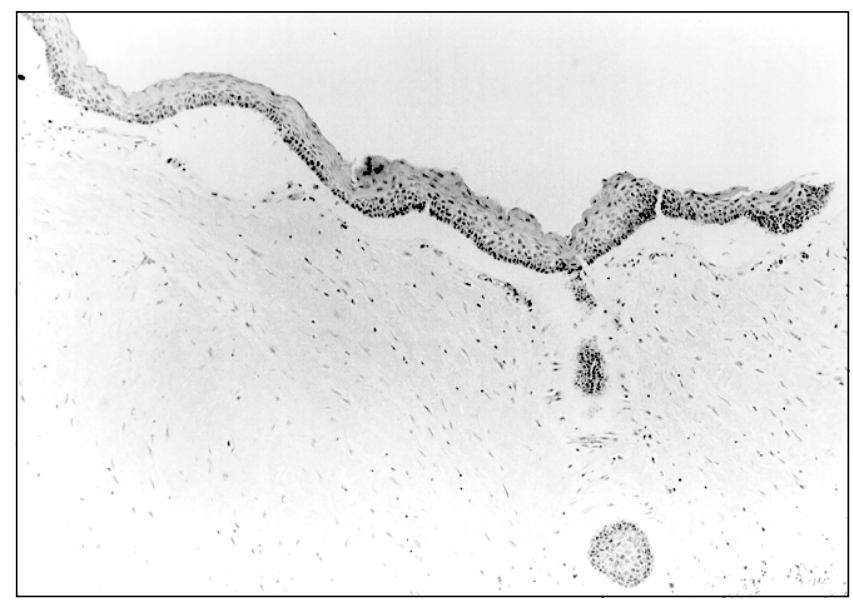

Figure 1) Characteristic lining epithelium of keratocysts: parakeratinized stratified squamous epithelium with a well defined basal layer, consisting of columnar cells with their hyperchromatic nuclei polarized away from the basal membrane. Note the microcysts in the wall of the keratocyst

volvement of adjacent soft tissues is possible. These features are more accurately imaged by computed tomography (CT) than conventional radiography (5).

OKCs are often clinically and radiographically indistinguishable from other benign cystic lesions $(16,17)$. Histopathological examination is required for definitive diagnosis. These cysts are characterized by the following: an ortho- or parakeratinized lining, typically corrugated and without rete ridge formation; a uniform seven to 10 epithelial cell layer thickness; and a well defined basal layer with prominent, polarized and intensely stained nuclei of uniform diameter $(12,18)$ (Figure 1). The cyst lumen may contain varying amounts of keratin. The growth of OKCs is likely due to high mitotic activity of the epithelium and low cystic fluid osmolality (9).

Various investigators have examined the histological variants of the OKC and their clinical features $(5,11,13,20$ 22). Crowley and co-workers (23) reviewed 449 cases of OKCs and categorized them based on their cystic lining. Results showed that $86.2 \%$ were parakeratinized, $12.2 \%$ were orthokeratinized and $1.6 \%$ had features of both, with no statistically significant difference between variants with respect to age, race, sex, presenting symptoms and clinical impression. The orthokeratinized form was more often associated with an impacted tooth $(75.7 \%$ compared with $47.8 \%$ for parakeratinized) and a reduced recurrence rate $(2.2 \%$, while parakeratinized OKCs recurred in at least $42.6 \%$ of cases) (22,23).

Brannon (5) reviewed 167 cases for which a provisional diagnosis was submitted and found that only $5 \%$ were correctly identified as OKC. Similarities exist between OKC and basal cell carcinoma in that they both exhibit locally invasive, slow spreading, nonmetastatic growth patterns; histologically both are characterized by darkly staining, polarized basaloid cells that are palisading and can show areas of keratin formation. In the basal cell nevus syndrome OKCs and basal cell carcinomas are known to occur together.
The OKC has also been contrasted to the ameloblastoma and dentigerous cyst with respect to mean age of occurrence, site predilection, radiographic presentation and recurrence rates.

The tendency for recurrence has been attributed to the OKCs unique histological, chemical and physical features $(8,20,22-24)$. Voorsmit, Stoelinga and van Haelst (25) demonstrated the presence of microcysts in the mucosa overlying recurrent lesions; they recommend excision of overlying mucosa at cystectomy. They proposed that recurrent keratocysts may develop in one of three ways: cystic epithelium left behind gives rise to new cyst formation; daughter cysts in the wall of the original cyst are left behind; or new keratocysts develop from epithelial offshoots of the basal layer of oral epithelium (25). While methods of treatment that might result in fewer recurrences have been suggested (7,25-27), there are relatively few long term follow-up reports demonstrating the efficacy of the procedures (25). Because of the propensity of OKCs to recur, a follow-up period of at least five years is recommended (28). However, case reports of recurrence as late as 37 years following primary cystectomy have been reported (29).

Although atypia of the cyst lining is uncommon and frank malignant degeneration is rare, squamous cell carcinoma arising from an $\mathrm{OKC}$ has been reported $(5,30,31)$. The summarized findings in reported cases of carcinomas arising within an OKC typically demonstrated a radiolucent lesion with occasional 'sunburst' appearance. The World Health Organization has included carcinomas arising from ex-odontogenic cysts as one of the three broad classifications of types of primary intra-osseous squamous carcinoma of the mandible.

\section{PATIENTS AND METHODS}

Six patients with extensive, new or recurrent OKCs of the maxilla were identified. Their presenting complaints were noted along with their age, sex and presence of orbital, nasal, sinus and/or dental involvement. Lesions were treated with combinations of enucleation, excision of overlying mucosa, application of Carnoy's solution, partial or hemimaxillectomy. Patients were monitored for recurrence and their follow-up periods were recorded.

\section{RESULTS}

The results of the six patients are summarized in Table 1. All six patients were female ranging in age from 14 to 66 years, mean 28.6 years. Four of the six lesions caused buccal swelling. One case produced orbital signs (proptosis) but did not actually encroach into the orbital cavity. Two cases involved the nasal cavity. All six lesions involved the maxillary sinus. Of the six lesions, five were associated with impacted teeth. Four of the six cases were recurrences. The lesions were treated by enucleation and curettage with or without Carnoy's solution, partial maxillectomy or hemimaxillectomy. The follow-up period ranged from one to five years (mean 3.2 years), with no recurrences noted so far post-treatment. The cases presented in Figures 2 and 3 were chosen as representative examples of extremes of the clinical spectrum. 
TABLE 1: Clinical summary of six extensive maxillary odontogenic keratocysts

\begin{tabular}{|c|c|c|c|c|c|c|c|c|c|c|}
\hline Case & BCNS & $\begin{array}{c}\text { Age } \\
\text { (years) }\end{array}$ & Chief complaint & Orbit & Sinus & Nasal & Tooth & $\begin{array}{l}\text { Recurrent } \\
\text { lesion }\end{array}$ & Treatment & $\begin{array}{c}\text { Follow-up } \\
\text { (years) }\end{array}$ \\
\hline 1 & No & 17 & 'Loose tooth eye strain' & $+^{*}$ & + & + & + & No & Enucleation & 3 \\
\hline 2 & Yes & 14 & Right buccal swelling & - & + & + & + & Yes & $\begin{array}{l}\text { Partial maxillectomy } \\
\text { Carnoy's solution }\end{array}$ & 3 \\
\hline 3 & Yes & 22 & Incidental finding & - & + & - & + & No & $\begin{array}{l}\text { Enucleation } \\
\text { Carnoy's solution }\end{array}$ & 3 \\
\hline 4 & No & 27 & Right buccal swelling & - & + & - & + & Yes & $\begin{array}{l}\text { Hemimaxillectomy } \\
\text { Carnoy's solution }\end{array}$ & 5 \\
\hline 5 & Yes & 26 & Left buccal swelling & - & + & - & + & Yes & $\begin{array}{l}\text { Partial maxillectomy } \\
\text { Carnoy's solution }\end{array}$ & 4 \\
\hline 6 & No & 66 & Right buccal swelling & - & + & - & - & Yes & $\begin{array}{c}\text { Enucleation } \\
\text { Carnoy's solution }\end{array}$ & 1 \\
\hline
\end{tabular}

All patients were female. ${ }^{\star}$ One lesion produced orbital signs (proptosis) but did not actually encroach into the orbital cavity. BCNS Basal cell nevus syndrome

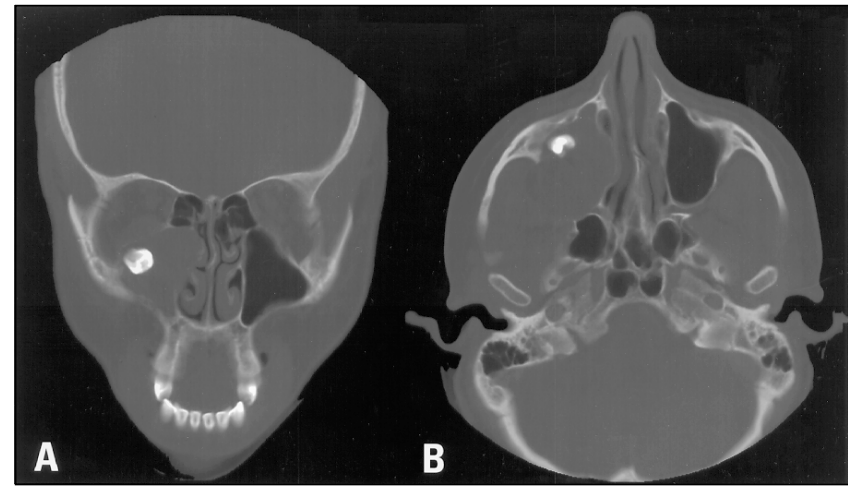

Figure 2) Case 1. A Coronal view from computed tomography (CT) showing cyst filling the right maxillary sinus with displaced tooth 18 situated directly below the right orbit. Orbital wall remains intact. $\mathbf{B}$ Axial view from CT illustrating medial encroachment on nasal cavity and expansion of the posterolateral sinus wall with thinning

\section{DISCUSSION}

There is significant controversy among clinicians concerning the optimal treatment of OKC. As a result, a wide range of treatments have been proposed (Table 2).

Proponents of a conservative approach to surgical management cite preservation of adjacent bone, soft tissue and dental structures, reduced morbidity and shorter hospital stays as some of the many advantage (6,32-34). These supporters feel that total enucleation or curettage with or without a 'periapical ostectomy' is adequate provided the entire specimen is excised with minimal or no fragmentation. The OKC's characteristically thin and friable lining, however, can make its removal in one piece difficult, if not impossible. Forsell et al (28) demonstrated that recurrence was significantly lower in cysts enucleated intact versus those in which the lining was removed piecemeal.

The high recurrence rate associated with the $\mathrm{OKC}$ has usually been attributed to the presence of satellite cysts. Brannon (5) demonstrated histologically that these daughter cysts are confined to the fibrous wall of OKCs; if the fibrous capsule is completely removed, no satellite cysts will remain to serve as a nidus for recurrence. Satellite cysts have not been demonstrated histologically or radiographically to oc-

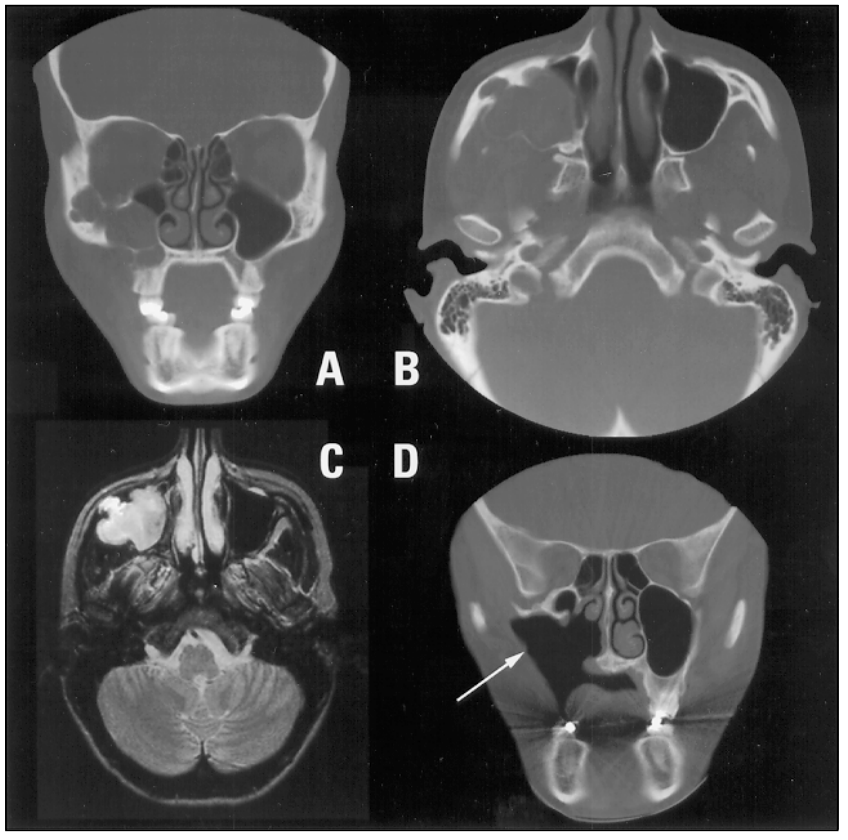

Figure 3) Case 4. A Coronal view from computed tomography (CT) showing a multilocular lytic lesion involving the right maxillary sinus and right zygoma. B Axial view from CT illustrating encroachment on right zygoma and posterolateral expansion and thinning of the right antral wall. $\mathbf{C} T_{1}$-weighted axial magnetic resonance image shows an irregular and well demarcated mass in the right maxillary region. It has a relatively high signal intensity compared with subcutaneous fat. D Coronal CT taken five years following hemimaxillectomy. Surrounding tissue remains recurrence free. Bone thickening of the remaining antral roof is a reaction to the previous operation (arrow)

\section{TABLE 2: Treatment options for odontogenic keratocysts}

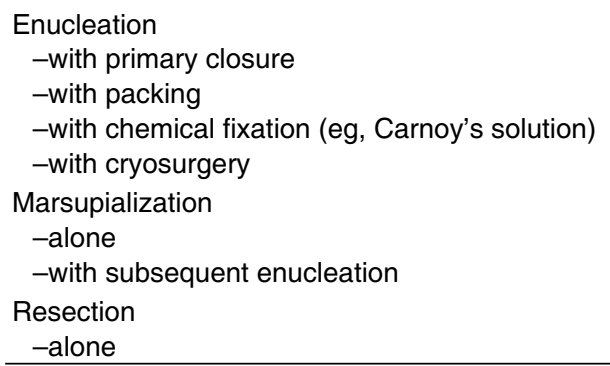


cur in osseous structures surrounding the parent cyst. Brannon (5) found that $16 \%$ of his series of OKCs demonstrated adherence to surrounding soft tissue structures. Any portion of adjacent soft tissue adherent to the cyst must be adequately excised, and some authors feel that overlying mucosa should be prophylactically excised (25).

Marsupialization is believed to accomplish a number of beneficial changes in the $\mathrm{OKC}$, including reduction in the cystic lumen, and alteration of the epithelium from thin and friable to thick and solid with no adhesion to adjoining structures. Brøndum and Jensen (24) treated 12 large cysts with marsupialization before primary cystectomy and found no recurrence during observation periods ranging from seven to 17 years.

Carnoy's solution was introduced by Cutler and Zollinger (35) in 1933 as a treatment modality for cysts and fistulae. Carnoy's solution comprises $6 \mathrm{~mL}$ absolute alcohol, $3 \mathrm{~mL}$ chloroform, $1 \mathrm{~mL}$ glacial acetic acid and $1 \mathrm{~g}$ ferric chloride. This solution has the qualities of moderate boney penetration with rapid local fixation of the lining cells and excellent hemostasis. Voorsmit, Stoelinga and van Haelst (25) reported a decreased recurrence rate in patients treated with careful enucleation, use of Carnoy's solution and excision of overlying mucosa $(2.5 \%)$, compared with enucleation alone $(13.5 \%)$. Carnoy's solution is thought to reduce the potential of recurrence by destroying cyst wall remnants and daughter cysts inadvertently left behind at the time of cyst removal.

The bony defects left in the maxilla by the OKCs in five of our six cases were treated with Carnoy's solution. A particular concern with the use of the solution is its diffusion through the thin orbital floor and potential damaging effects on the orbital contents.

\section{REFERENCES}

1. Phillipsen HP. On keratocysts in the jaws. Tandlaegebladet 1956;60:963-80.

2. Shear M. Primordial cysts. J Dent Assoc S Afr 1960;15:211.

3. Pindborg JJ, Hensen J. Studies on odotogenic cyst epithelium II. Clinical and roentgenographic aspects of odontogenic keratocysts. Acta Pathol Microbiol Scand 1963;58:283.

4. Cawson RA. Essentials of Dental Surgery and Pathology, 4th edn. London: Churchill Livingstone, 1984:168-71.

5. Brannon RB. The odontogenic keratocyst. A clinicopathologic study of 312 cases. Part I. Clinical features. Oral Surg Oral Med Oral Pathol 1976;42:54-72.

6. Browne RM. The odontogenic keratocyst. Clinical aspects. Br Dent J 1970;128:225-31

7. Bramley PA. Cysts of the jaws and oral soft tissues In: Moore JR, ed. Surgery of the Mouth and Jaws. Oxford: Blackwell Scientific Publications, 1985:415-39.

8. Kakarantza-Angelopoulose E, Nicolatou O. Odontogenic keratocysts: Clinicopathologic study of 87 cases. J Oral Maxillofac Surg 1990;48:593.

9. Shear M. Cysts of the Oral Regions, 3rd edn. Stoneham: ButterworthHeinemann, 1992:6-7.

10. McIvor J. The radiological features of odontogenic keratocysts. Br J Oral Surg 1972;10:116-25.

11. Woolgar JA, Rippin JW, Browne RM. A comparative study of the clinical and histological features of recurrent and non-recurrent odontogenic keratocysts. Oral Surg Oral Med Oral Path 1987;16:124-8.

12. Shafer WG, Hine MK, Levy BM. A Textbook of Pathology. Philadelphia: WB Saunders and Co, 1974.
Long-lasting neurotoxicity has been reported in cases involving the mandible where the inferior alveolar nerve has been located within the cyst treated with Carnoy's solution. Frerich and co-workers (36) studied the critical exposure time for Carnoy's solution by decorticating $1 \mathrm{~cm}$ of the inferior alveolar nerve in rabbits and soaking it with modified Carnoy's solution for periods ranging from 2 to 5 mins. Those authors concluded that contact of a peripheral nerve with Carnoy's solution carries a time-related risk of producing acute sensory impairment and recommend restricting exposure to 3 mins or less whenever the nerve is unprotected.

The extent to which Carnoy's solution might diffuse through maxillary bone into the orbital cavity is unknown. Notwithstanding the potential effect on the peripheral nerves in this area, the possibility of necrosis of orbital fat and subsequent enopthalmus cannot be ruled out and deserves further study. For these reasons the region of the cystic cavity adjacent to the orbital floor was carefully protected with petroleum jelly gauze before application of Carnoy's solution.

Long term follow-up of OKCs with annual radiological examination is recommended for at least five years following surgery and will detect most recurrences (24). However, because it is often difficult to diagnose recurrence in the maxilla, some authors recommend CT or magnetic resonance imaging (MRI) for patient follow-up $(10,14)$. In consideration of the extent of the lesions presented, and the often insidious nature of their growth pattern, we recommend that bi-annual patient examination with plain radiography be supplemented with yearly CT scan or MRI for the first five years to detect the presence of recurrent lesions, with annual clinical examinations thereafter.

13. Haring JI, Van Dis ML. Odontogenic keratocyst: A clinical, radiological and histopathologic study. Oral Surg Oral Med Oral Path 1988;66:145-53.

14. MacDonald-Jankowski DS. The involvement of the maxillary antrum by odontogenic keratocysts. Clin Radiol 1992;45:31-3.

15. Goaz GW, White SC. Oral Radiology: Principles and Interpretation, 2nd edn. St Louis: The CV Mosby Company, 1987:491-8.

16. Killey HC, Kay LW. Benign Cystic Lesions of the Jaws: Their Diagnosis and Treatment, 2nd edn. London: Churchill-Livingstone, 1972.

17. Stafne EC, Gibilisco JA. Oral Roentgenographic Diagnosis, 4th edn. Philadelphia: WB Saunders and Co, 1975:159-60.

18. Regezi JA, Sciubba JJ. Oral Pathology - Clinical-Pathological Correlations. Philadelphia: WB Saunders and Co, 1989:313-6.

19. Toller PA. Autoradiography of explants from odontogenic cysts. Br Dent J 1971;131:57-61.

20. Zachariades N, Papanicolou S, Triantafyllou D. Odontogenic keratocyst: Review of the literature and report of 16 cases. J Oral Maxillofac Surg 1985;43:177.

21. Ahlfors E, Larsson A, Sjogren S. The odontgenic keratocyst: A benign cystic tumour? J Oral Maxillofac Surg 1984;42:10.

22. Wright JM. The odontogenic keratocyst: Orthokeratinized variant. Oral Surg Oral Med Oral Pathol 1981;51:609.

23. Crowley TE, Kaugars GE, Gunsolley JC. Odontogenic keratocysts: A clinical and histological comparison of the parakeratin and orthokeratin variants. J Oral Maxillofac Surg 1992;50:22-6.

24. Brøndum N, Jensen VJ. Recurrence of keratocysts and decompression treatment. Oral Surg Oral Med Oral Path 1991;72:265-9. 
25. Voorsmit RACA, Stoelinga PJW, van Haelst UJGM. The management of keratocysts. J Maxillofac Surg 1981;9:228-36.

26. Stoelinga PJW. Kaakkysten. Stasleütholen: NV-Liden, 1971.

27. Ephros H, Lee HY. Treatment of a large odontogenic keratocyst using the Brosch procedure. J Oral Maxillofac Surg 1991;49:87.

28. Forssell K, Forssell H, Kahnberg K-E. Recurrence of keratocysts: a longterm follow-up study. Int J Oral Maxillofac Surg 1988;17:25-8.

29. Oikarinen VJ. Keratocyst recurrences at intervals of more than 10 years: case reports. Br J Oral Surg 1990;28:47-9.

30. Dabbs DJ, Schweitzer RJ, Schweitzer LE, Mantz F. Squamous cell carcinoma arising in recurrent odontogenic keratocyst: Case report and literature review. Head Neck 1994;16:375-8.
31. Anand VK, Arrowood JP, Krolls SO. Malignant potential of the odontgenic keratocyst. Otolaryngol Head Neck Surg 1994;111:124-9.

32. Meiselman F. Surgical management of the odontogenic keratocyst: Conservative approach. J Oral Maxillofac Surg 1994;52:960-3.

33. Rud J, Pindborg JT. Odontgenic keratocysts: A follow-up study of 21 cases. Part 1. Clinical features. Oral Surg 1976;42:54.

34. Eyre J, Zakrzewska JM. The conservative management of large odontogenic keratocysts. Br J Oral Maxillofac Surg 1985;23:195-203.

35. Cutler EC, Zollinger R. Sclerosing solutions in the treatment of cysts and fistulae. Am J Surg 1933;XIX:411-8.

36. Frerich B, Cornelius C-P, Wietholter H. Critical time of exposure of the rabbit inferior alveolar nerve to Carnoy's solution. J Oral Maxillofac Surg 1994;52:599-606. 